\title{
Measles genotypes D4 and G3 reintroduced by multiple foci after 15 years without measles virus circulation, Gipuzkoa, the Basque Country, Spain, March to June 2011
}

G Cilla (gcilla@telefonica.net)1,2, M Montes ${ }^{1,2}$, J Artieda ${ }^{3}$, L Piñeiro ${ }^{1}$, L Arriola ${ }^{3}$, E Pérez-Trallero ${ }^{1,2,4}$

1. Microbiology Department, Hospital Universitario Donostia-Instituto Biodonostia, San Sebastián, Spain

2. Biomedical Research Centre Network for Respiratory Diseases (CIBERES), San Sebastián, Spain

3. Public Health Division of Gipuzkoa, Basque Government, and CIBERESP, San Sebastián, Spain

4. Department of Preventive Medicine and Public Health, Faculty of Medicine, University of the Basque Country, San Sebastián, Spain

Citation style for this article:

Cilla G, Montes M, Artieda J, Piñeiro L, Arriola L, Pérez-Trallero E. Measles genotypes D4 and G3 reintroduced by multiple foci after 15 years without measles virus circulation, Gipuzkoa, the Basque Country, Spain, March to June 2011.

Euro Surveill. 2011;16(43):pii=19997. Available online: http://www.eurosurveillance.org/ViewArticle.aspx?Articleld=19997

Article published on 27 October 2011

During a three-month period in spring 2011, 23 cases of measles occurred in seven independent outbreaks in a region in Spain with around 700,000 inhabitants, where the disease had been eliminated since 1997. High vaccination coverage and rapid diagnosis allowed implementation of containment measures and this prevented spread of the disease. Except for the first outbreak which affected 10 cases, each of the other six outbreaks caused a maximum of three secondary cases.

In spring 2011, 23 measles cases were detected in Gipuzkoa, a region in Spain bordering the south of France, where no measles cases had been reported since the second half of the 1990s [1]. The cases were not grouped into a single outbreak but belonged to several outbreaks, with distinct origins. This report describes measles circulation in Gipuzkoa from March to June 2011 and the control measures adopted and implemented.
Gipuzkoa is a territory of the Basque Country in northern Spain and it has a population of around 700,000 inhabitants. Coverage of the measles-mumps-rubella (MMR) vaccine has been over $90 \%$ since 1987 for the first dose in children aged 12 months and since 2002 for the second dose in children aged four years, respectively. Since 2007, coverage for the two MMR vaccine doses has been over $95 \%$. Measles is included in the mandatory disease notification system in Spain.

\section{Description of the outbreaks}

Between 23 March and 29 June 2011, 23 cases of measles were detected through the Microbiological and Epidemiological Surveillance System of the Basque Country and they were distributed in seven independent outbreaks (Table).

In the outbreaks described here, specific IgM detection was performed through indirect ELISA (Enzygnost Anti-Measles Virus/IgM, Siemens, Germany). Viral RNA detection was carried out in pharyngeal swabs, saliva

TABLE

Measles outbreaks in Gipuzkoa, the Basque Country, Spain, March-June 2011

\begin{tabular}{|l|c|c|c|c|}
\hline Outbreak start (2011) & Index case & Number of secondary cases & Type of outbreak & Genotype (number of genotyped cases) \\
\hline March & 1 adolescent & 3 children +6 adults & Institutional & D4 (9) \\
\hline April & 1 adult & 0 & Isolated case & D4 (1) \\
\hline May & 1 child & 0 & Isolated case & D4 (1) \\
\hline May & 2 children & 2 children +1 adult & Familial-school & D4 (4) \\
\hline May & 1 adult & 0 & Isolated case & GA \\
\hline May & 1 adult & 1 adolescent +1 adult & Familial & D4 (2) \\
\hline June & 1 adult & 1 adult & Familial & \\
\hline
\end{tabular}

NA: not available.

${ }^{\text {a }}$ Child: aged 0-14 years; adolescent: aged $15-20$ years; adult: aged $\geq 21$ years. 
and/or urine through amplification of a nucleoprotein (N) gene fragment [2]. The viral RNA samples were processed in order to obtain the genotype [3]. The genetic sequences obtained were deposited in the GenBank (access number JN695499 to JN695503).

All but two cases were confirmed by viral RNA detection; one of these two cases was diagnosed by the presence of specific IgM. The second case occurred in a preschool aged boy, whose parents refused collection of biological samples from their child. However, the boy showed symptoms typical of the disease and was from a family with two confirmed measles cases. Virological tests excluded measles in 21 patients with rash in whom measles had initially been considered as diagnosis but later rash proved to be caused by other viral infections.

The first outbreak was the largest, with 10 cases, and occurred in a centre where people live collectively. Every day, the index case went to study in a neighbouring town in the Atlantic Pyrenees, a district in France where there were numerous measles cases registered during that period (incidence rate ranged from 15 per 100,000 population to 30 per 100,000 population) [4]. This outbreak affected four children, four workers in the centre and two more persons (one of them was working in a hospital and got infected after contact with a child

\section{FIGURE}

Phylogenetic tree of 20 measles viruses detected in Gipuzkoa compared with six reference strains, the Basque Country, Spain, March-June 2011

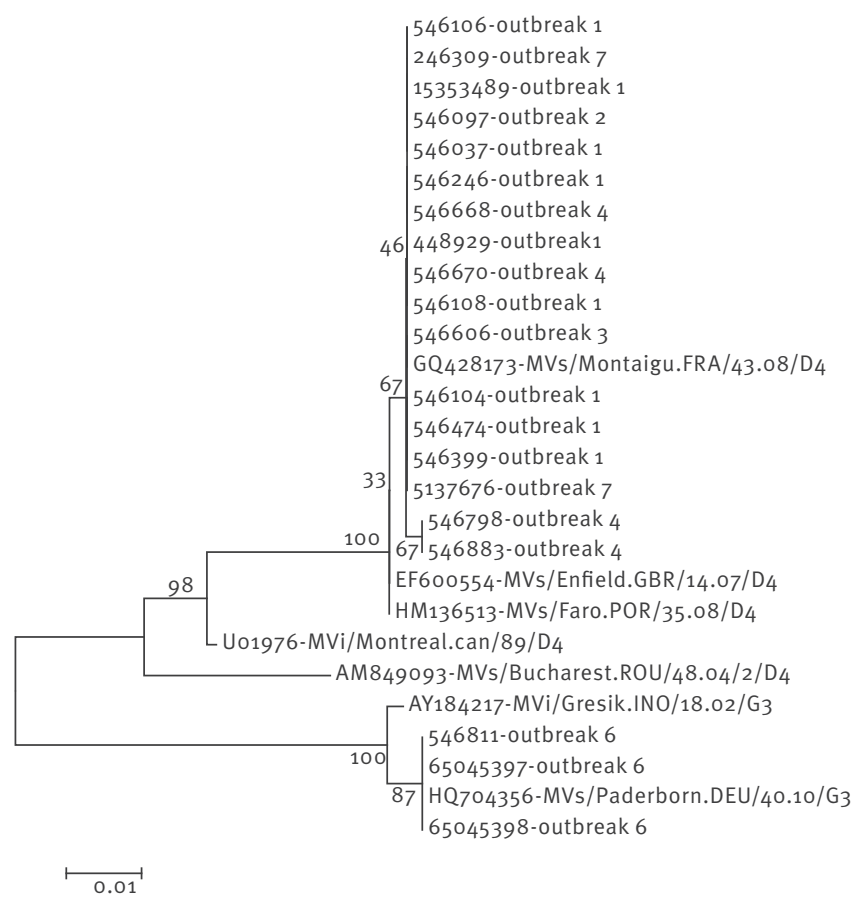

The tree was constructed through the neighbor-joining method with 1,000 bootstrap replications and shows bootstrap values in the branches. of this outbreak in the paediatric emergency room of the hospital).

The remaining six outbreaks were smaller, mainly affecting families that were against vaccination. In all outbreaks, except one whose origin was unknown, the index case got infected outside the Basque Country. Two index cases had visited France during the 7 to 21 days before contracting the infection, two further coindex cases had visited northern France (EuroDisney) and three had visited other regions of Spain (Andalusia, Madrid and (atalonia). Seventeen of the 23 affected individuals, including the eight index cases had not been vaccinated, four had received one dose and one had received two doses, while the vaccination status of one affected individual was unknown. Four persons were hospitalised due to respiratory complications following measles (two persons in their thirties, one in their twenties and an infant under one year of age). The virus was genotyped in 20 patients: 17 belonged to genotype $\mathrm{D}_{4}$, including all those where the index case had been infected in France, and three belonged to $\mathrm{G}_{3}$ but the place of infection was unknown.

\section{Control measures}

Persons with suspected measles were recommended to stay away from school or work and remain at home for seven days after the onset of the rash or until the diagnosis was excluded, if established before the end of the seven-day period. Children and adults from household or school, aged less than 40 years, who had had contact with a measles case and who had not previously received two vaccine doses, were offered MMR vaccination. All contacts, or in the case of children, their legal guardians, were informed about the symptoms of measles and were advised to seek medical attention if they experienced one or more of the following symptoms: fever, rash, red eyes, malaise and sore throat. In addition, the Department of Public Health alerted the network of primary care physicians with regards to the epidemiological situation of measles through electronic reports sent by email or through telephone calls.

\section{Discussion and conclusion}

After more than a decade with no measles cases detected in the region [1], seven separate outbreaks were detected within a few months in this area in the Basque Country. This striking viral activity coincided with a substantial increase in measles circulation in other European regions, in particular in neighbouring France [5]. This report shows that imported cases of measles pose a risk even to regions with high vaccination coverage in which endemic measles has been eliminated. In Gipuzkoa, the spread of the disease was probably contained by the high vaccination coverage in previous years and the rapid response of the different partners involved in the primary healthcare system and surveillance services. As in other recent outbreaks in Europe [6] most affected individuals had not been vaccinated, infection in persons who had received two vaccine doses being exceptional. Four of the seven 
outbreaks were related to groups who were against vaccination.

Unvaccinated people pose a substantial risk to the general public, and if they refuse vaccination, they should restrict their contacts with the general population (school, day-care) in epidemic situations. In one of the outbreaks in Gipuzkoa, there was resistance to comply with the containment measures recommended. Notwithstanding the absence of any legislation, the community has a responsibility to protect those who cannot be vaccinated - this can be done by ensuring herd immunity. More than half of the cases occurred in young persons, without prior contact with the virus, who were born around the time when vaccination campaigns started (1975-1990).

The D4 genotype, the main genotype detected, was predominant in recent outbreaks in France, Spain and other European countries [5,7]. The $\mathrm{G}_{3}$ genotype was introduced in Europe in 2010 and one imported case has been reported in Spain [8]. Despite an exhaustive epidemiological investigation, we were unable to determine the origin of the outbreak caused by the $\mathrm{G}_{3}$ genotype.

Reaching and consolidating high vaccination coverage (with two doses) is essential to eradicate measles, a World Health Organization goal for Europe by 2015 [9]. However, the risk of measles resurgence will remain for as long as the virus continues to circulate in other regions of the world. Therefore, rapid diagnosis and notification, which allow implementation of containment measures, are crucial in the fight against this disease.

\section{References}

1. Cilla G, Basterretxea M, Artieda J, Vicente D, Pérez-Trallero $\mathrm{E}$. Interruption of measles transmission in Gipuzkoa (Basque Country), Spain. Euro Surveill. 2004;9(5): $\mathrm{pii}=468$. Available from: http://www.eurosurveillance.org/ViewArticle. aspx?Articleld $=468$

2. Mosquera Mdel M, de Ory F, Moreno M, Echevarría JE. Simultaneous detection of measles virus, rubella virus, and parvovirus B19 by using multiplex PCR. J Clin Microbiol. 2002; 40(1):111-6.

3. El Mubarak HS, van de Bildt MW, Mustafa OA, Vos HW, Mukhtar MM, Ibrahim SA, et al. Genetic characterization of wild-type measles viruses circulating in suburban Khartoum, 1997-2000. J Gen Virol. 2002;83(Pt6):1437-43.

4. Institut de Veille Sanitaire (InVS). Epidémie de rougeole en France. Actualisation des données de surveillance au 5 octobre 2011. [Measles outbreak in France. Update on surveillance data 5 October 2011]. Paris: InVS. 6 Oct 2011. Available from: http://www.invs.sante.fr/Dossiers-thematiques/Maladiesinfectieuses/Maladies-a-prevention-vaccinale/Rougeole/ Points-d-actualites/Archives/Epidemie-de-rougeole-enFrance.-Actualisation-des-donnees-de-surveillance-au-5octobre-2011

5. European Centre for Disease Prevention and Control (ECDC). European monthly measles monitoring (EMMO), June 2011. Stockholm: ECDC; 2011. [Accessed 26 Oct 2011]. Available from: http://ecdc.europa.eu/en/publications/ Publications/2011_June_measles_montly.pdf

6. Muscat M. Who gets measles in Europe? J Infect Dis. 2011; 204 Suppl 1: S353-65.

7. Freymuth F, Vabret A. Measles, a re-emerging disease in France? Clin Microbiol Infect. 2011;17(6):793
8. Brown KE, Mulders MN, Freymuth F, Santibanez S, Mosquera $M M$, Cordey S, et al. Appearance of a novel measles $\mathrm{G}_{3}$ strain in multiple European countries within a two month period, 2010. Euro Surveill. 2011;16(17): pii=19852. Available from: http://www.eurosurveillance.org/ViewArticle. aspx?Articleld $=19852$

9. World Health Organization (WHO). Regional Committee for Europe, Sixtieth session. Resolution. Renewed commitment to elimination of measles and rubella and prevention of congenital rubella syndrome by 2015 and sustained support for polio-free status in the WHO European Region. Moscow, 13-16 September 2010. [Accessed 26 Oct 2011]. Available from http://www.who.int/immunization/sage/3_Resolution_EURO RC60_eRes12.pdf 